\title{
Représentations Picturales sur les poignards Qajars (1193-1343 H./ 1779- 1925 J.C.) ${ }^{1}$
}

\author{
Radwa M. Omar \\ Lecturer of Islamic Archaeology - Faculty of Tourism and Hotels Management - \\ Suez Canal University
}

\begin{abstract}
Résumé
L'Iran était un des pays islamiques les plus célèbres pour la fabrication et la décoration des armes. Voulant restaurer la gloire de ses ancêtres, elle a fondé une industrie basée sur les traditions artistiques sassanides, qui ont marqué l'époque de luxe et de grandeur de la Perse.
\end{abstract}

Cette recherche traite un des armes métallurgique les plus en usage durant l'époque Qajar, les poignards, qui jouissent d'un attrait particulier pour les guerriers, ils étaient, non seulement utilisés à des fins de défenses et de combats, mais aussi durant les cérémonies et les réceptions officielles devant les dirigeants militaires.

D'autre part, les garnitures exubérantes des poignards Qajars, dorés et incrustés de pierres précieuses étaient carrément utilisés pour désigner les rangs militaires.

$\mathrm{Au}$ début de l'époque qajar, les artistes désiraient revenir aux traditions artistiques classiques de l'ère sassanide, néanmoins, bientôt touchés par les influences européennes, les œuvres qajars ont commencé à avoir un nouveau goût.

Divers sortes de poignards ont été exécutées sous les Qajars, avec une lame droite, courbée, à seul ou à double tranchant, desservis de fourreaux en bois ou en argent, et décorés d'un amalgame de garnitures.

Cette recherche met en relief les différents représentations picturales sur les poignards Qajars, à partir de nombreux spécimens exposés dans des musées en Iran et à l'étranger; ces représentations s'étale sur une vaste gamme de thèmes artistiques, qui comprend des portraits de Šāhs, des femmes, et d'autres représentations figuratives comme certains animaux, symboliquement liés à la mythologie iranienne.

Mots clés: Qajar- poignard- représentation picturale -femme- animaux- influences européennesdamasquinage- incrustation- émail- gravure - forage.

\section{Introduction sur l'Art Qāiār}

Après l'agitation et les troubles du dix-huitième siècle, en Perse, la montée en puissance de la dynastie qājār (1193-1343 H./ 1779- 1925 J.C.) a marqué une nouvelle paix et l'unité pour le pays. Les šāhs qājārs comptaient beaucoup sur les arts visuels pour confirmer et consolider leur nouvelle position. Un aspect de leur image publique les liée à la longue histoire de la Perse et ses anciennes dynasties, mais une autre composante de leur identité était comme modernisateurs et réformateurs.

Le premier šāh qājār, Ağā Muhammad Khān (r. 1199- 1211 H./ 1785-1797 J.C.), portait principalement sur la consolidation de la position de la famille contre le Zands de Shiraz (1163-1208 H./ 1750-1794 J.C.), son successeur Fatḥ 'Alī S̄āh (r. 1211- 1250 H./ 1797 à 1834 J. C.), qui jouissait d'une position plus sûre, a consacré une grande attention à façonner l'image impériale qājār.

Pour glorifier les qājārs et les distinguer de leurs prédécesseurs, il a changé les aspects cérémonials de la cour, ainsi que la titulature royale et les insignes impériaux. Cette compagne de renforcement qu'il a guidé, comprenait la construction de nombreuses mosquées, connues sous le nom de «Mosquées du Šāh», ainsi que les nouveaux palais dans la capitale de Téhéran. ${ }^{2}$

Dans le domaine des arts appliqués, le palais Gulistan à Téhéran témoignait d'une richesse artistique incontestable, comportant de magnifiques œuvres d'art sous forme de lustres, de vases, de peintures des portraits des šāhs, en plus de divers cadeaux précieux. ${ }^{3}$

\section{Règne de Nāṣir al- Dīn Šāh et influences européennes}

Nāṣir al- Dīn Šăh (r. 1264- 1313 H./ 1848 à 1896 J.C.), a eu le règne le plus long de tous les souverains iraniens, malgré son autocratie orientale, il était un homme de son temps, il a réformé l'État en ministères, il a encouragé l'acquisition des sciences modernes, et a importé des techniques modernes comme la photographie, alors, son règne était de plus en plus reconnue comme un temps de changement significatif dans la société persane, de même, marqué par une avancée profonde, économique et culturelle, des Européens. ${ }^{4}$ 
Notant que l'influence la plus évidente était l'impact des idées, et de la technologie occidentale, qui ont accompagné les diplomates, les conseillers militaires et techniques, les marchands, les missionnaires, les voyageurs, et les artisans, qui affluaient dans la Perse du XIX ${ }^{\text {ème }}$ siècle, d'une part à cause du rétablissement des relations diplomatiques entre l'Iran et l'occident, tels que la Russie, l'Angleterre, la France et l'Espagne qui a marqué le début de la dynastie, ${ }^{5}$ et d'autres part, des influences indirectes des pays voisins comme l'Arménie, la Géorgie et l'inde. ${ }^{6}$

Cela s'ajoute aux puissances coloniales européennes, surtout de la part de la Russie, qui occupaient plusieurs provinces persanes, par conséquent, ces provinces, dont les plus importantes sont Bukhāra, Samarqand et Téhéran, jouaient le rôle du passage de l'art européen en Perse, fortement émergé depuis le début de la seconde moitié du règne de la dynastie qājār. ${ }^{7}$

$\mathrm{Au}$ cours de ces échanges culturelles, la Perse a connu une période d'assimilation et d'adaptation, ce qui a engendré une société saturée par les influences européennes. ${ }^{8}$

La tradition européenne a affecté deux aspects importants de l'art persan; le sujet et la teinte, comme il est détaillé plus tard dans cette recherche.

L'art Qājār, solidement enraciné dans la tradition iranienne, a cherché à incorporer les vertus de l'Europe, tout en rejetant ses vices inhérents. Les résultats étaient dynamiques, on a vu les tonalités de couleur de l'art européen comme les bruns, jaunes foncés, et rouges brillants, assimilées dans le cadre de sa propre tradition artistique, alors que la deuxième moitié du règne Qājār est marquée par la réflexion de cette dualité. ${ }^{9}$

\section{L'importance des armes dans l'Islam}

Dans le coran, l'importance accordée aux armes est claire, et le Prophète Muhammad qui avait une expérience militaire considérable, comme c'était le cas avec la plupart de ses contemporains en Arabie, était également très clair dans ses instructions concernant leur importance. On lui attribue le hadìth: «Les épées sont les clés du Paradis» ${ }^{10}$. Les paroles du Prophète sur les questions militaires ont eu un effet puissant sur les sociétés musulmanes, ${ }^{11}$ et il était normal que les entrepôts des califes soient comblés de toutes sortes d'armes. ${ }^{12}$

Le transfert d'armes d'une société à l'autre est généralement le résultat du commerce ou de la guerre. Les matières premières militaires de l'élite ont également été largement échangées. ${ }^{13}$

Les armes étaient toujours très acceptables comme cadeaux aux dirigeants et les militaires de haut rang, comme indiqué par «Ibn Battūṭa», qui a cité l'exemple du souverain indien «Muḥammad bin Ṭughluq» ce dernier a fait un don d'une charge de chameau de flèches. Il a même indiqué que n'importe quel don envoyé à un autre tribu devrait toujours être fourni avec un grand nombre de cadeaux précieux qui devraient inclure des épées, des lances, des poignards, des arcs, des flèches et d'autres armes.

En 886 H./1481 J.C., un incident a marqué l'importance évidente des dons d’État- donnés pour des raisons commerciales et diplomatiques -qui comportaient très souvent des armes; les membres d'une ambassade envoyés par le chef Deccani «Šams al-Dīn Muhammad Šāh» ont été arrêtés à Djeddah par le gouverneur mamelouk local, alors qu'ils se rendaient au sultan ottoman «Bayāzīd II» avec des cadeaux qui incluaient un poignard à clous de diamants, les cadeaux ont été confisqués et cela a tellement scandalisé les Ottomans que les chroniques ottomanes contemporaines attribuent à cet incident la guerre ottomane-mamelouke de 890-96 H./ 1485-91 J.C. ${ }^{14}$

\section{Les poignards Qājārs}

L'Iran était toujours connu par son excellence dans la fabrication et la décoration des armes, elle est devenue l'un des plus grands centres artistiques dans ce domaine dans le Moyen et le Proche-Orient. ${ }^{15}$

En général, les armes sont considérées des œuvres métallurgiques d'importance primordiale puisqu'elles étaient utilisées comme un moyen de défense, ${ }^{16}$ plusieurs genres d'armes ont été minutieusement exécutés telles les épées, les kārds ${ }^{17}$ et les poignards.

Le poignard, en arabe «khanjar» (pl. khanājir), est une arme qui consiste en une poignée sous la forme de la lettre «I», et une lame courbée à double tranchants, plusieurs manuscrits persans ont décrit le poignard comme une arme utilisée dans les combats rapprochés, ${ }^{18} \mathrm{~d}$ 'habitude, il était porté dans la ceinture, à droite ou à gauche. ${ }^{19}$ Il n'y a pas d'évidence qu'il était en usage en Perse avant le XV ${ }^{\text {ème }}$ siècle. ${ }^{20}$

Ils étaient parmi les armes qui jouissaient d'un attrait particulier pour les guerriers, pas seulement utilisés pour la guerre et les combats, mais ils étaient utilisés dans les cérémonies officielles et les présentations devant les dirigeants militaires, considéré comme le plus grand champ pour montrer ces armes, ${ }^{21}$ qui désignaient parfois les rangs militaires. 
Considéré comme un des plus beaux exemples d'armes persans, la plupart des poignards qājārs était exécutés sous forme d'une poignée droite en forme de «I», et une lame courbée - droite pour la première moitié, après quoi elle se courbe fortement- à double tranchants et une nervure médiane.

Selon «Khorasani», la forme de la lame du poignard a subi un développement au cours des siècles, durant le $\mathrm{XV}^{\mathrm{ème}}$ siècle, le poignard avait une lame toute droite, mais toujours à double tranchants, durant les siècles suivants, VXI $^{\text {̀̀me }}$ et XVII ${ }^{\text {ème }}$ siècles, la forme de la lame est changée et a commencé à être de plus en plus courbée. $^{22}$

Bien que la majorité des lames des poignards sont en acier damassé ${ }^{23}$, il y a aussi des exemples de lames en acier ordinaire, la nervure médiane court directement de la base jusqu'à la pointe de la lame, se terminant par un point renforcé, et en général, la poignée est faite d'un solide morceau d'ivoire de morse, mais, il y a d'autres exemples où elles étaient faites en métal. ${ }^{24}$

\section{Matériaux et techniques}

Sous les Qajars, plusieurs matériaux ont été utilisés dans la fabrication des poignards, tant que le laiton, le cuivre, l'acier, l'argent, le bois et l'ivoire, de même, l'or et l'argent étaient largement en usage dans la décoration ainsi qu'une gamme de pierres précieuses.

Les poignards ont été décorés avec une variété de techniques telles que la gravure, la peinture, le damasquinage, l'incrustation, et l'émaillage. ${ }^{25}$

\section{Le damasquinage}

Le terme «damasquiné», en arabe «takfit» signifie une technique produisant des effets décoratifs par contraste de couleurs des différents métaux choisis. Ces effets sont obtenus en incrustant par martelage des fils, généralement d'or ou d'argent, des petites plaques ou des feuilles de métal, dans un fond de métal différent, généralement en fer ou en acier, sur lequel des sillons et des surfaces ont été gravé au préalable. ${ }^{26}$

\section{Incrustation}

L'incrustation consiste à enchâsser dans une matière quelconque, sans grande valeur, une autre plus précieuse, les pierres précieuses et semi- précieuses étaient utilisées dans cette technique comme l'agate, la turquoise et le lapis- lazuli. ${ }^{27}$

La technique de l'incrustation sur métal offre plusieurs variétés; l'orfèvrerie champlevée, où l'artisan insère des plaquettes de matière différente dans des cavités ménagées au burin, et l'orfèvrerie cloisonnée où les pierres sont disposées dans les logettes formant un motif en relief soudé sur la plaque. ${ }^{28}$

\section{Émaillage}

L'émail est une matière fondante, composée de différents minéraux (silice, kaolin et oxydes métallique), laquelle, vitrifiée et plus ou moins opaque (fritte), peut recevoir différentes couleurs et être appliquée à l'aide du feu sur certains ouvrages d'or, d'argent ou de cuivre, pour les orner. Ce mélange, proche d'une pâte, se vitrifie sous l'action de la température, lors de la cuisson.

Les techniques du champlevé, du cloisonné, et de l'émail peint, ont été utilisées dans la décoration des poignards Qajars. ${ }^{29}$

Émail champlevé

Le métal généralement utilisé était le cuivre, le principe fondamental était de loger l'émail dans des creux réservés à cet effet, d'une profondeur de demi-millimètre, puis, le burin précise les bords pour donner un aspect net.

Émail cloisonné

C'est une technique qui consiste à créer des cloisons cernées de minces rubans métalliques ou de fils d'or fixés sur la surface à émailler, ces cloisons peuvent être fixées sur le cuivre nu et par soudure à l'argent, et l'émail est ensuite introduit au cœur des alvéoles ainsi formées. ${ }^{30}$

\section{Décor}

La décoration des poignards Qajars couvre presque la totalité des poignées et le renfort du talon de la lame. Le décor se caractérise par un style exubérant et un usage flamboyant de la couleur, avec un goût européen durant sa deuxième moitié, où la maîtrise technologique a rendu possibles des formes virtuoses de décoration.

Une caractéristique particulièrement importante de l'art Qajar est la richesse de son iconographie; les figures sont affichées soit seules ou en paires, elles sont placées dans des médaillons, rectangulaires, à angles 
arrondis, polylobés, pointus ou en losange, et définies par un cadre ou délimitées par les tiges des arabesques. Ces médaillons étaient réservés sur fond de rouleau floral en spirale finement travaillé et entrelacé. $^{31}$

Les motifs floraux étaient d'une importance indéniable, rares sont les pièces qui ne comportent pas ce genre de décoration.

Les fleurs (en particulier les roses et les iris), le feuillage et les fruits fonctionnent à la fois comme motifs centraux et supports.

Outre les motifs floraux et animaux, une partie dominante de l'ornementation est confinée à la calligraphie, les poignards étaient souvent décorés d'une grande variété de passages coraniques et d'invocations pieuses, qui fonctionnaient comme des expressions de piété, comme de puissantes défenses sous la forme de talismans, ou simplement comme ornements visuellement agréables.

\section{Les différents thèmes ornementaux représentés sur les poignards Qajars}

- Thèmes relatifs à la religion

L'art islamique était plutôt orienté vers l'aniconisme, selon les ḥadīths, toute représentation figurative était bannie par l'Islam, «Les anges n'entrent pas une maison abritant une photo ou un chien» ${ }^{32}$ assez fréquente, une large gamme de petits motifs figuratifs (humains, animaux et créatures imaginaires) a été abondamment utilisée dans la période Qajar.

La représentation des personnages religieux existait sur les poignards Qajars, comme celle d'Adam et Eve, ainsi que la représentation des soufis qui était fréquemment rencontrée sur divers genres d'arts appliqués.

Signalons encore que ces figures relatives à des thèmes religieux étaient exécutées d'une façon assez réaliste en raison du développement du soufisme et de l'influence européenne étendue. ${ }^{33}$

\section{- Thèmes de combat d'animaux}

Les combats d'animaux sont également décrits sur les poignards; on y voit souvent un prédateur attaquant une proie, toujours occupant le renfort du talon de la lame du poignard.

Dans la plupart des scènes illustrées sur les poignards, le rapace était sous la forme d'un lion terrassant un cerf ou une autre proie. Selon Jean Paul Roux, le roi s'étant assimilé au lion, il voulait représenter sa victoire sur ses ennemis. ${ }^{34}$

En revanche, il existait une interprétation théologique pour la représentation du lion sur les épées-et bien entendu les poignards - puisque la tradition sunnite et chiite admet que l'épée du Prophète a été léguée par lui à son beau-fils 'Alī, le quatrième calife et la personnification de la chevalerie arabe, connue sous le nom de lion victorieux de Dieu «Asad-allah ul-ghālib». De 'Alī, il est descendu à son fils Hưsayn qui a été martyrisé en 60 H./ 680 J.C., il paraît que c'est la source du motif de lion sculpté sur la base des lames des épées et des poignards perses au XIX ${ }^{\text {ème }}$ siècle, destiné à renforcer l'utilisateur. ${ }^{35}$

D'ailleurs, Khorasani a fourni une autre explication concernant notamment la représentation du combat entre lion et taureau, amplement utilisé dans la décoration des lames des poignards Qajars, selon lui, ces animaux représentaient des emblèmes de force, strictement liés à la mythologie persane, trois hypothèses sont démontrées comme il suit:

1. Une interprétation qui assume que cette scène représente le changement des saisons puisque le lion était un symbole d'été et du jour, tandis que le taureau symbolisait l'hiver et la nuit.

2. Etant donné que le lion représente le soleil et le taureau est l'image de la lune, cette scène pouvait présenter le cycle du jour et de la nuit.

3. Le lion pouvait servir à souligner le fait qu'une force assez puissante comme celle du taureau n'arrive pas à vaincre un lion, une image qui insiste sur la futilité de contester la supériorité du roi et l'importance de l'accepter comme réalité indiscutable. ${ }^{36}$

\section{- Thèmes romantiques}

Des couples amoureux sont fréquemment représentés d'une manière réaliste, toutefois, ces scènes étaient d'une pudeur évidente durant la première moitié de l'époque Qajar, tandis qu'à la deuxième partie de l'époque -où l'influence européenne était dominante- l'érotisme était clair dans les scènes amoureuses. ${ }^{37}$

\section{- Thèmes relatifs à l'aristocratie}

Un des piliers les plus importants de l'art Qajar, était la représentation de la vie aristocrate, les rois, les princes, le luxe des palais, une tendance vérifiée par le fait que la plupart des artistes à l'époque ont été attirés par la vie de luxe qu'ils matérialisaient par leurs œuvres; souvent répétées sur les poignées de poignards, comme les scènes qui faisaient partie d'un répertoire traditionnel de passe-temps princiers, quelques figures 
portent des gobelets à leurs lèvres et brandissent des pichets de vin dans un jardin avec des bouteilles et des fruits; certains dorment avec leurs têtes reposantes sur leurs genoux, illustrant le topos de la littérature persane de «plonger la tête sur le genou de la contemplation», d'autres sont montrés assis sur de grandes chaises à dossier haut de la manière européenne. ${ }^{38}$

\section{- Thèmes relatifs à la femme}

Avant l'époque Qajar, la femme faisait partie du thème décoratif de l'œuvre artistique, mais, presque jamais représentée seule, néanmoins, sous les Qajars, la femme était un des thèmes les plus abordés par les artistes, puisque à cette époque, elle a commencé à occuper presque la totalité de la décoration sur les œuvres des arts appliqués $^{39}$, cette influence féminine sur l'art Qajar est due à l'importance de son rôle dans le palais du roi ${ }^{40}$ qui, d'habitude, avait beaucoup d'épouses, de concubines, des musiciennes et des danseuse. Cette présence remarquable a incité les artistes de la montrer dans divers occasions et en différentes tenures, elle a été présentée jeune ou vieille, à la maison ou à l'extérieur, mère ou amoureuse, les artistes ont désigné des œuvres complètes à la représentation de la femme. ${ }^{41}$

Signalons encore que l'iconographie de la femme s'est évoluée durant la seconde partie de l'époque qajar où l'influence européenne était en vigueur, on peut constater que les traits du visage féminin sont devenues plutôt européens, même la coiffure s'est changée et les cheveux entourent librement le visage, avec un chapeau sur la tête. ${ }^{42}$

D'ailleurs, l'illustration des tenues féminines est carrément changée pour avoir une apparence européenne qui n'avait rien à voir avec les vêtements traditionnels souvent représentés durant la première moitié de l'époque qajar. ${ }^{43}$

\section{Exemples des poignards Qajars}

Poignard $\mathbf{n}^{\circ} \mathbf{I}$ (Publié pour la première fois)

Date: Poignard du règne de «Fatḥ 'Alī Šāh» (1800- 1801),

Matière: Lame en acier damasquiné, avec un fourreau en bois doré et émaillé et incrusté de pierres précieuses.

Conservation: Conservé au musée de Vicrtoria \& Albert

$\mathbf{N}^{\circ}$ d'inventaire: $1602 \& \mathrm{~A}-1888$

Dimensions: 35.5 × $6 \mathrm{~cm}$.

\section{Description:}

Ce poignard a été donné comme don de «Fatḥ 'Alī Šāh» au capitaine «John Malcolm» qui était un délégué diplomatique de la Compagnie de l'Inde Orientale britannique, le dernier a été en mesure de conclure un premier accord pour la compagnie avec le Šāh en 1801.

La lame de poignard est en acier damasquiné d'or, le renfort du talon de lame est décoré d'ornementation florale sous forme de branches entrelacées. ${ }^{44}$ (Pl. I)

Le manche du poignard est incrusté de pierres précieuses formant des fleurs à huit pétales; de couleur vert foncé, rouge et cristal.

Quant au fourreau du poignard, il est en bois doré, et recouvert d'émail de diverses couleurs; rose, bleue, vert et blanc. La décoration consiste en des motifs floraux; un médaillon en forme de losange occupe le centre de chaque face du fourreau, garnis de fleurs de lotus et d'autres fleurs à six et sept pétales.

Les deux montures du fourreau comportent le même décor de motif floral. La bouterolle est recouverte d'or.

Poignard $\mathbf{n}^{\circ}$ II (Publié pour la première fois)

Date: début du XIX ${ }^{\text {ième }}$ siècle.

Matière: Lame en acier damassé, manche en cuivre émaillé et fourreau en bois émaillé.

Conservation: Conservé au Métropolitain Museum of Art

$\mathbf{N}^{\circ}$ d'inventaire: $36.25 .684 \mathrm{a}, \mathrm{b}$

Dimensions: 43.3 x $5.1 \mathrm{~cm}$.

\section{Description:}

Ce poignard était un don fait au musée par George C. Stone, en 1935.

La lame en acier damassé et damasquiné d'or, sur le renfort du talon, le damasquinage est exécuté en quatre parties regroupées en deux de chaque côté de la nervure médiane, deux comportant un décor épigraphique et les autres garnis de nœuds d'arabesques. ${ }^{45}$ (Pl.II. b- II. c).

La poignée est en cuivre émaillé, la peinture est labourée dans des médaillons, polylobés ou en forme de losanges, remplis par l'illustration de divers genres de fleurs. 
Le fourreau, un vrai œuvre d'art, est en bois émaillé, avec des couleurs brillantes et des motifs floraux luxuriants qui sont typiques aux émaux peints à l'époque Qajar, tandis que le rose opaque, le bleu et le blanc prédominent, la couleur de fond est un vert translucide profond appliqué à un sol d'or scintillant. (Pl. II.d) L'artiste a signé son travail sur le fourreau, «Maḥmūd». (Pl. II.e) ${ }^{46}$

Poignard $\mathbf{n}^{\circ}$ III (Publié pour la première fois)

Date: 1800-01, début du XIX ${ }^{\text {ième }}$ siècle.

Matière: Lame en acier damassé et poignée en ivoire, le fourreau en bois recouvert de cuir.

Conservation: Conservé à Harvard Art Museum

No d'inventaire: 1958.131.A-B

Dimensions: 35 x $5.2 \mathrm{~cm}$.

Description

La lame de ce poignard, qui est un modèle d'acier finement damasquiné d'or, a été faite en 1800-01, environ 30 ans avant la poignée. L'inscription qui orne la garde indique qu'il a été fait à Kirman, par l'ordre de Hassan Khān, connu sous le nom de «Ağā Khān-1̄ Beglarbegi» ${ }^{47}$.

Un côté du manche porte son portrait ${ }^{48}$, tandis que l'autre côté est garnis par le portrait du souverain Qajar Muhammad Šāh (r. 1250- 1264 H./ 1834-1848 J.C.), portant un poignard très semblable à celui-ci plié dans sa ceinture. (Pl. III)

Poignard $\mathbf{n}^{\circ}$ IV (Publié pour la première fois)

Date: début du XIX ${ }^{\text {ième }}$ siècle.

Matière: Lame en acier et manche en argent, le fourreau en bois laqué.

Conservation: Conservé au musée Victoria \& Albert

$\mathbf{N}^{\circ}$ d'inventaire: $582 \mathrm{~A}-1876$

Dimensions: 36 x $6 \mathrm{~cm}$.

Description

Le poignard consiste en une lame courbée, en acier damasquiné d'or et un manche en argent, finement gravé et incrusté de pierres précieuses comme la turquoise et l'agate.

Le fourreau est revêtu de bois laqué, l'ornementation consiste en trois médaillons, le premier est garnis d'un oiseau de proie attaquant un canard, tandis que le médaillon central est polylobé, et illustré d'une jeune fille portant une belle robe de couleurs rouge et vert foncé, et elle porte sur la tête un toque ondulé, le troisième médaillon porte la représentation de deux canards. Les trois médaillons sont exécutés sur un fond de motifs floraux, des rosettes colorées et dorées. (Pl. IV)

En outre, il faut souligner que ce poignard remonte au début du XIXème siècle, un fait qui nourrit la réflexion concernant la représentation de la femme durant la première moitié de l'époque Qajar, dans cet exemple, il est évident que les traits du visage, la coiffure et les vêtements appartiennent aux formes artistiques traditionnelles qui dominaient avant l'invasion des influences artistiques européennes.

Poignard $\mathbf{n}^{\circ} \mathbf{V}$ (Publié pour la première fois)

Date: début du XIX ${ }^{\text {ième }}$ siècle.

Matière: Lame en acier et manche en cristal de roche, le fourreau en bois laqué avec une chape en argent ciselé.

Conservation: Conservé au musée Victoria \& Albert

$\mathbf{N}^{\circ}$ d'inventaire: $720 \mathrm{~A}-1889$.

Dimensions: $39 \times 5.4 \mathrm{~cm}$.

\section{Description}

Lame courbée et a nervure médiane, en acier finement damasquiné d'or sur le renfort de talon de lame, avec un motif calligraphique minutieux. Le manche est en cristal de roche.

Le fourreau de ce joli poignard est laborieusement travaillé, exécuté en bois laqué. Sa décoration est divisée en deux parties; la première est garnie de deux médaillons ovales sur un fond de motifs floraux dorés, portants des représentations figuratifs, l'un comporte une fille qajarienne portant une coupe aux lèvres, l'autre est décoré d'un jeune homme portant une fleur.

Etant donné que ce poignard remonte au début du XIX ${ }^{\text {ème }}$ siècle, on peut déduire que les vêtements, la coiffure, ainsi que les traits des visages des personnages sont traditionnels.

La deuxième partie du fourreau est magnifiquement couverte d'une chape en argent forgée et ciselée par des motifs floraux. (Pl. V) 
Poignard $\mathbf{n}^{\circ}$ VI (Publié pour la première fois)

Date: début du XIX ${ }^{\text {ième }}$ siècle

Matière: Lame en acier, courbée et manche en ivoire

Conservation: Conservé au Musée National d'Art d'Azerbaïdjan

Description

Lame en acier courbée, à double tranchants et à arête centrale, damasquiné d'or, décorée d'arabesques ciselés. (Pl. VI. a) La poignée est en ivoire, l'illustration figurative est exécutée par la manière de forage en relief, on y voit une représentation assez rare d'Adam et Eve, les corps nus et les bras entrelacés, les gardes de la poignée sont décorées d'ornementations calligraphiques. (Pl. VI. b)

L'œuvre remonte à la première moitié de l'époque Qajar, on remarque la tendance des artistes à aborder des thèmes religieux significatifs sur les différents spécimens d'arts appliqués.

Poignard $\mathbf{n}^{\circ}$ VII (Publié pour la première fois)

Date: Début du XIX ${ }^{\mathrm{ème}}$ siècle.

Matière: Lame en acier, et manche en ivoire, le fourreau en argent incrusté de pierres précieuses.

Conservation: Conservé au musée Victoria \& Albert

$\mathbf{N}^{\circ}$ d'inventaire: $573 \mathrm{~A}-1876$.

Dimensions: 36 x $5 \mathrm{~cm}$.

\section{Description}

Ce poignard a été exécuté au début de l'époque Qajar, la lame est en acier, à double tranchant, et à nervure médiane, le talon est décoré d'une représentation figurative d'un lion attaquant un cerf, sur un fond d'arabesque, exécutée de la manière de forage en relief.

Le manche en ivoire, orné de motifs floraux gravés en relief, il se termine par une plaque d'argent, poli et clouté de pierres précieuses.

Le fourreau est en argent minutieusement incrusté de pierres précieuses comme la turquoise et l'agate dans des médaillons ronds et ovales. (Pl. VII)

Poignard $\mathbf{n}^{\circ}$ VIII (Publié pour la première fois)

Date: Deuxième moitié du XIX ${ }^{\text {ème }}$ siècle.

Matière: Lame en acier, et manche en jade vert, le fourreau en bois laqué.

Conservation: Conservé au musée Victoria \& Albert

$\mathbf{N}^{\circ}$ d'inventaire: $719 \mathrm{~A}-1889$.

Dimensions: $40 \times 5.5 \mathrm{~cm}$.

\section{Description}

Poignard en acier, la lame est courbée, à double tranchants et à nervure médiane, damasquiné d'or en simples formes d'arabesques, réalisés par la manière de gaufrage.

La poignée est en jade vert décoré de fleurs dorées ouvertes.

Le fourreau est en bois laqué et doré, des représentations figuratives sont reparties en trois médaillons ovales, sur un fond de décorations florales multicolores et dorées.

Le médaillon central, plus grand que les deux autres qui le flanquent, porte le dessin d'une fille qajarienne, exécuté d'une manière traditionnelle qui caractérise la première moitié de l'époque Qajar, tandis que les deux autres médaillons sont occupés par le dessin de deux oiseaux, on peut constater la représentation du ciel bleu à l'arrière-plan des trois dessins. (Pl.VIII)

Poignard $\mathbf{n}^{\circ} \mathbf{I X}$ (Publié pour la première fois)

Date: Deuxième moitié du XIX ${ }^{\mathrm{eme}}$ siècle

Matière: Lame en acier, et manche en ivoire, le fourreau en bois laqué.

Conservation: Conservé au musée Victoria \& Albert

$N^{\circ}$ d'inventaire: $574 \& A-1876$

Dimensions: 38.5 x $5.6 \mathrm{~cm}$.

Description

Poignard d'acier courbé, à double tranchants et à arête centrale, le renfort du talon de la lame contient des motifs exécutés d'une manière de forage et poinçonnage, représentent un dessin pictural d'un lion attaquant une proie. 
La poignée est en ivoire, ornée d'une représentation figurative d'un couple familial avec un enfant (en bas), exécutée par la technique de forage. Les deux gardes rectangulaires encadrant la poignée aux extrémités sont décorées de calligraphie. (Pl. IX. a)

Le fourreau est en bois laqué et doré; sa décoration consiste en un médaillon polylobé central, occupé de la peinture d'une belle fille qajarienne portant une fleur; le dessin est exécuté sur un fond vert foncé.

Les deux montures du fourreau sont recouvertes par deux belles chapes en argent ciselées et incrustées de turquoise. (Pl. IX .b)

La représentation picturale sur la poignée indique que ce poignard a été exécuté durant la deuxième moitié de l'époque Qajar où la dominance des trais européens est assez évidente, le couple avec des tenues et des coiffures qu'on ne rencontre presque jamais sur les œuvres appartenant à la première phase de l'art Qajar; le jeune homme porte un chapeau à plumes sur la tête et des pantacourts, tandis que la femme est coiffée et vêtue comme les européennes. ${ }^{49}$

Poignard $\mathbf{n}^{\circ} \mathbf{X}$ (Publié pour la première fois)

Date: Deuxième moitié du XIX ${ }^{\text {ème }}$ siècle

Matière: lame en acier, et manche en cuivre émaillé.

Conservation: Conservé au Metropolitan Museum of Art

$\mathbf{N}^{\circ}$ d'inventaire: 36.25 .683

Dimensions: 34.8 x $6.2 \mathrm{~cm}$.

\section{Description}

Ce poignard était un don fait au musée par George C. Stone, en 1935.

Lame en acier courbée, à double tranchants et nervure médiane, le renfort du talon est orné, sur une face par la représentation d'un lion dévorant une proie, et de l'autre côté, par des oiseaux sauvages.

Le manche du poignard estampé en cuivre émaillé de diverses couleurs; une face est décorée d'un médaillon ovale central, bordé par la peinture d'une belle dame portant un chapeau sur la tête, sur fond clair, ce médaillon est flanqué de deux autres médaillons polylobés, plus petits, décorés de motifs floraux, sous forme de rosettes à triples et quadruples pétales, exécutées en or sur un fond d'émail bleu foncé. (Pl. X. a)

L'autre face du manche est occupée par trois médaillons; ressemblants à ceux peints sur la première face, pourtant, le médaillon central sur cette face est presque sous forme de losange et garni de motifs floraux colorés sur un fond d'émail doré. (Pl. X. b)

De toute évidence, ce poignard est exécuté sous l'époque d'influence européenne, comme il est incontestable de la représentation picturale de la femme au style européen.

Poignard $\mathbf{n}^{\circ} \mathbf{X I}$ (Publié pour la première fois)

Date: Deuxième moitié du XIX ${ }^{\mathrm{eme}}$ siècle

Matière: Lame en acier, et manche en ivoire

Conservation: Conservé au Métropolitain Museum of Art

$\mathbf{N}^{\circ}$ d'inventaire: 36.25 .1058

Dimensions: 35.8 × $6 \mathrm{~cm}$.

Description

Ce poignard était un don fait au musée par George C. Stone, en 1935.

Poignard à lame en acier, à double tranchants et arête médiane, le renfort du talon de sa lame est orné, sur les deux côtés, d'une représentation picturale d'un prédateur terrassant une proie, exécutée par la technique de forage.

La poignée en ivoire est riche de décoration figurative; sur une face apparaît un couple d'amants sous un parapluie, gravé en haut relief ( $\mathrm{Pl}$. XI. a), tandis que l'autre plaque est décorée, au centre, d'une femme entourée de deux jeunes filles et deux autres, plus petites, qui apparaissent devant elle. (Pl. XI. b)

Les gardes de la poignée sont sous la forme de médaillons rectangulaires à ornementations calligraphiques. Il apparaît clairement, d'après l'exécution du décor de ce poignard, qu'il est influencé par l'art européen, à la fois dans les traits ou les vêtements de style étranger, minutieusement gravés pour mettre en relief les moindres détails comme les plissés et les boutons.

Poignard $\mathbf{n}^{\circ}$ XII (Publié pour la première fois)

Date: Deuxième moitié du XIX ${ }^{\text {ème }}$ siècle 
Matière: Lame en acier, et manche en ivoire

Conservation: Conservé au Métropolitain Museum of Art

$\mathbf{N}^{\circ}$ d'inventaire: 96.5 .138

Dimensions: 38.7 x $5.9 \mathrm{~cm}$.

Description

Ce poignard fait partie de la collection de John Stoneacre Ellis Collection, donné au musée comme don de Mme. Ellis et Augustus Van Horne Ellis, en 1896.

Lame en acier damassé, courbée, à double tranchants et à nervure médiane.

Le renfort du talon de la lame est garni, sur ces deux faces, de la scène traditionnelle d'un lion terrassant une proie. (Pl. XII. a)

La poignée en ivoire est magnifiquement travaillée, avec tant de détails artistiques; l'iconographie occupe les deux faces avec des représentations figuratives féminines:

La première (Pl. XII. b), montre une dame, aux traits et coiffure européens, les cheveux contournant le visage, portant une belle robe garnie de motifs floraux, avec une ceinture tombante sur le devant. De sa main droite, elle tient un enfant nu, l'autre main est attachée à la tige d'une fleur laborieusement détaillée.

Les deux gardes de la poignée, en forme de médaillons rectangulaires, portent une ornementation épigraphique qui veut dire: «La poignée de ton poignard saisit le monde».

La deuxième (Pl. XII. c), montre une jeune fille, toujours au style européen, ses longs cheveux sont libres autour du visage et sur les épaules, elle porte un petit chapeau pointu, une jolie robe et des talons, dans sa main gauche, un bâton sur lequel se pose un oiseau. Le fond est garni de motifs floraux de différents genres. Les deux gardes de la poignée portent, à leur tour, un décor épigraphique. L'œuvre est gravé à haut- relief. L'amour de la nature et la beauté est bien manifesté dans ce poignard. ${ }^{50}$

\section{Conclusion}

- Les poignards qajars jouissaient d'un attrait particulier pour les guerriers et les hauts fonctionnaires, qui les utilisaient pour la défense, dans les cérémonies et les réceptions officielles devant les dirigeants militaires.

- Les poignards faisaient partie des cadeaux présentés des rois ou des sultans aux dirigeants et les militaires de haut rang.

- Les poignards dorés et incrustés de pierres précieuses étaient parfois utilisés pour désigner les rangs militaires.

- Il existait différents types de poignards, à lame droite ou courbée, à seul ou à double tranchants, ces formes ont été élaborées à travers différentes phases de développement.

- Diverses techniques ont été utilisées dans la fabrication et la décoration des poignards, dont certaines étaient une continuation des méthodes décoratives déjà en vigueur durant les époques précédentes, comme le damasquinage, la gravure, l'incrustation et l'émaillage.

- La prédominance des influences européennes sur l'art iconographique au cours de la deuxième moitié de l'époque Qajar, où les formes traditionnelles de l'art étaient profondément renouvelées, ainsi, le début du règne de Nāṣir al-Dīn Šāh, montre une nouvelle orientation artistique distinguée.

- Les représentations picturales sur les poignards qajars sont diversifiées, humaine, animale ou florale, chacune avait son rôle décoratif et symbolique à la fois.

- L'époque Qajar est considérée comme l'âge d'or de la représentation de la femme sur les plupart des arts appliquées, et inévitablement sur les poignards, cela indique l'importance qu'elle a acquise durant cette époque. Sa représentation a été forcément influencée par les traits artistiques européens, en termes de tenues et de coiffure.

- La représentation des combats d'animaux était une scène répétitive sur les talons des lames des poignards, souvent le rapace était sous la forme d'un lion terrassant un cerf ou une autre proie, ce qui voulait désigner, mythologiquement, la victoire du roi sur ses ennemis.

- Les motifs floraux ont été utilisés comme une toile de fond pour le thème principal; arbres, roses et fleurs témoignaient de l'amour de la nature qui consistait un trait fondamental dans l'œuvre. 
كانت إيران من الأقطار الإسلامية التي الثتهرت بصناعة الأسلحة وزخرفتها منذ أقدم عصور ها، وأصبحت من أعظم المر اكز الفنبة شأناً في

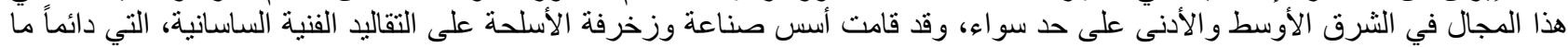

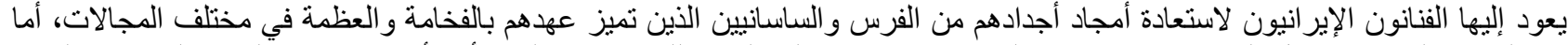

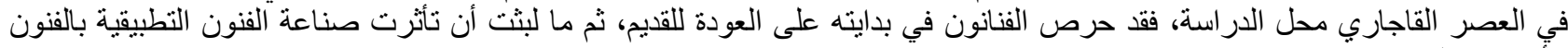
الأوروبية الو افدة.

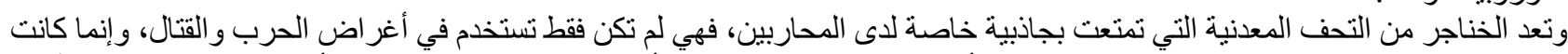

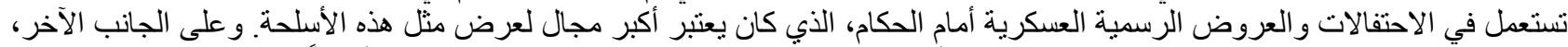

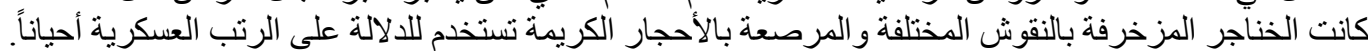

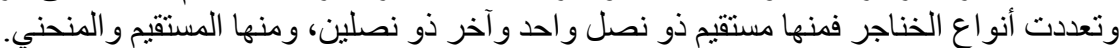

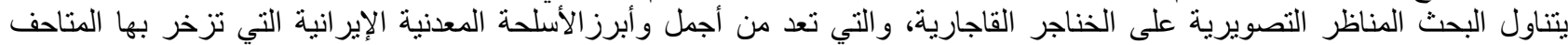

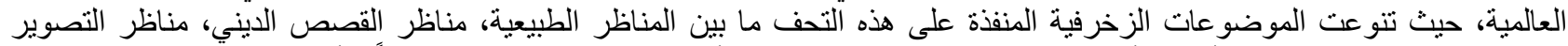

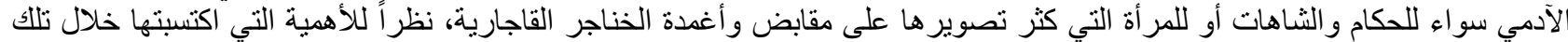
الفترة.

ويعرض البحث نماذج للخناجر القاجارية المعروضة في مجموعة من المتاحف العالمية، مصحوبة بدر اسة لطرق الصناعة، وعرض للألماذج التي تتنمي للمرحلة الفنية الكلاسيكية، والأخرى المتأثرة بالفنون الأوروبية.

التكلمات الدالة: خنجر - نصل - غمد - تصوير آدمي - تصوير ديني- المر أة- تأثير ات أوروبية ـ تكفيت- زخرفة بالمينا - ترصيع- الحفر - 


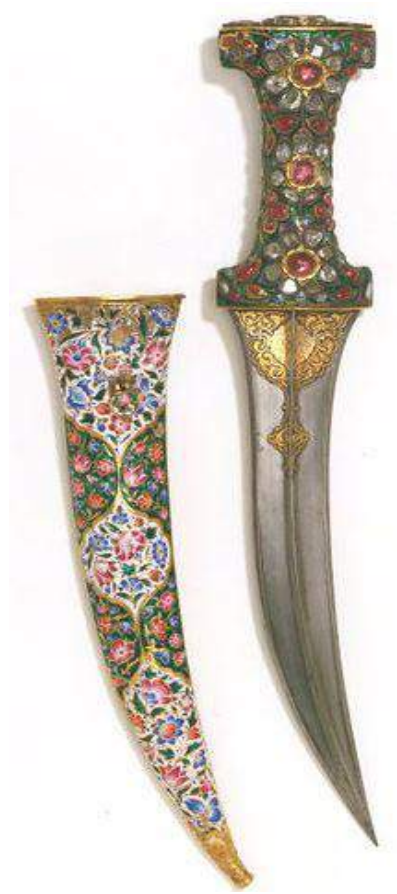

Pl. 1- Poignard en acier damasquiné et fourreau en bois doré et émaillé - règne de Fath 'Alī Šāh (1801) Musée Victoria \& Albert $\mathrm{N}^{\circ} 1602 \& A-1888$

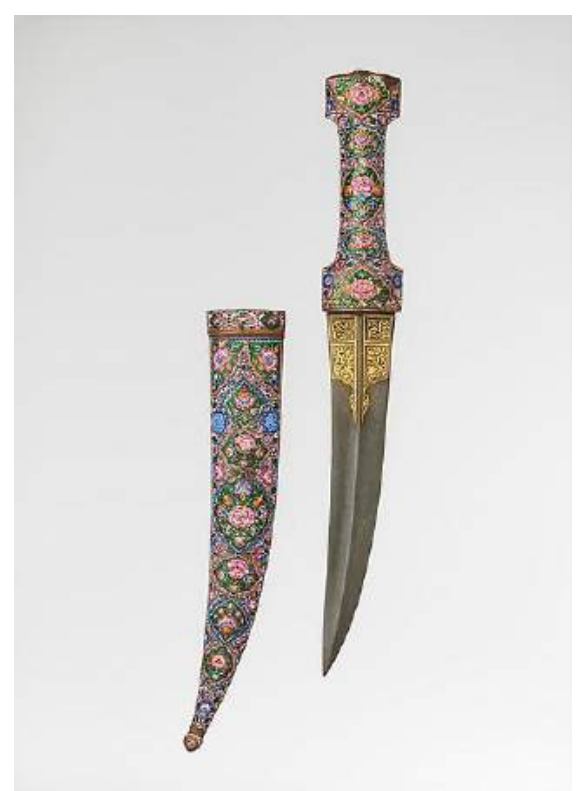

Pl. 2. B- Détails de la garniture de la manche et fourreau

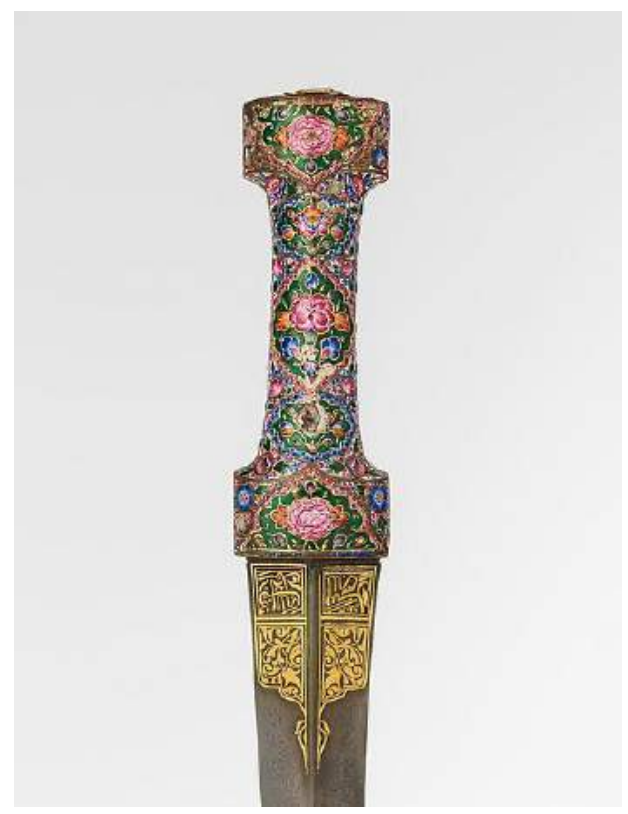

Pl. 2. A- Lame en acier damassé, poignée et le talon de lame 


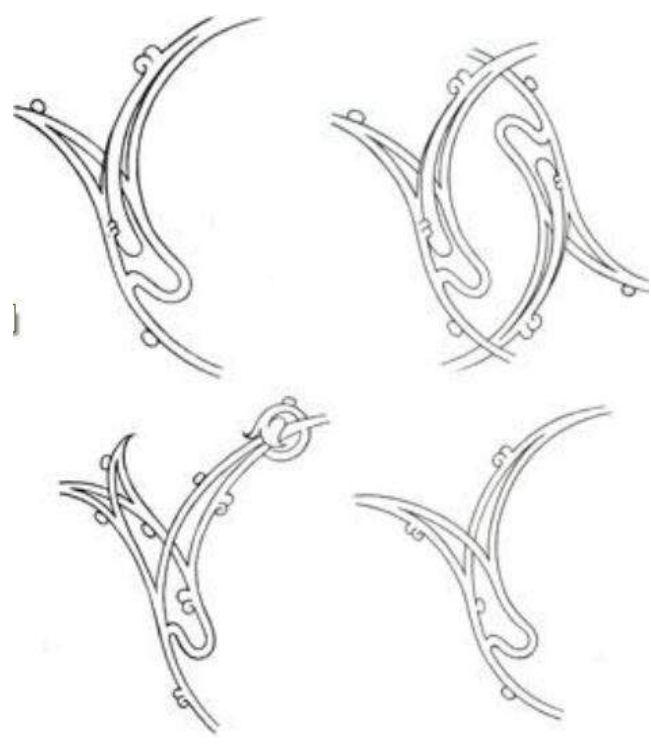

Pl. 2. C- Motifs de nœud arabesque
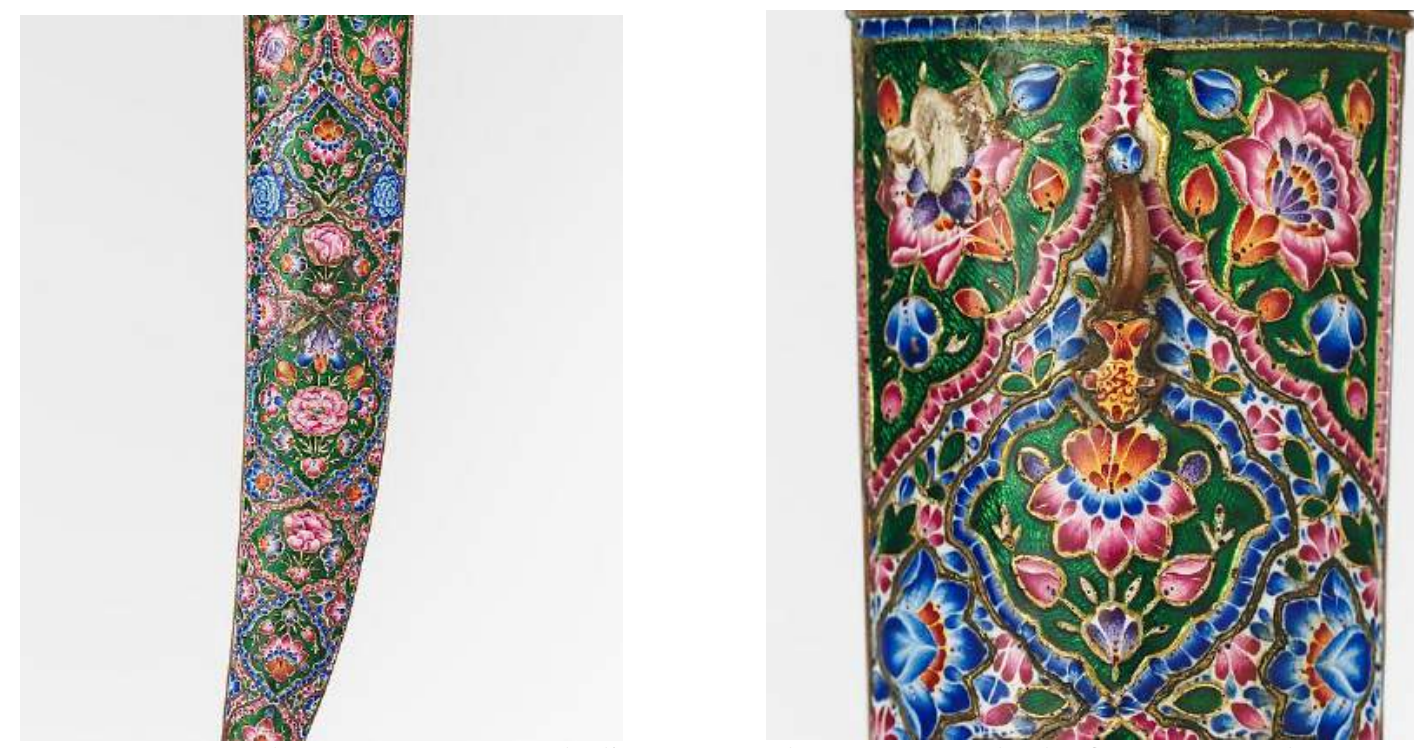

Pl. 2. E- Signature de l'artisan Pl. 2. D- Détails du fourreau en bois émaillé

Poignard en acier damassé, manche en cuivre émaillé et fourreau en bois émaillé Métropolitain Museum of Art $\mathrm{N}^{\circ}$ 36.25.684a, b 


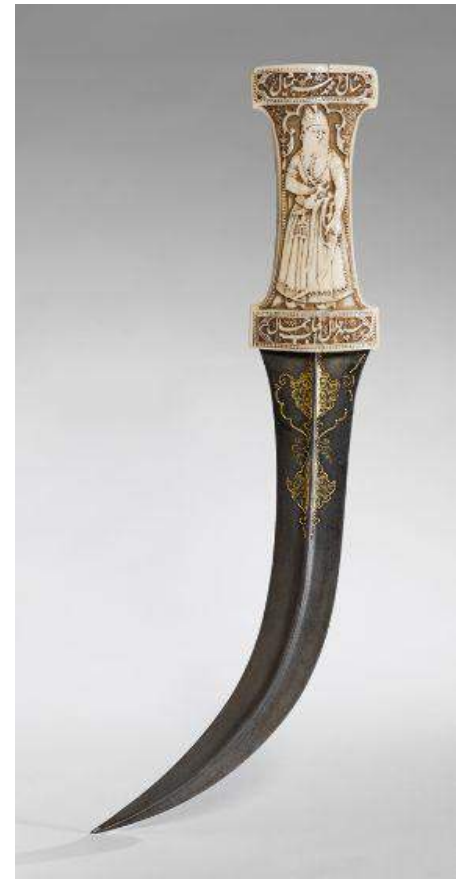

Pl. 3- Poignard en acier damasquiné d'or et poignée en ivoire (1801-1835)

Harvard Art Museum No 1958.131.A-B

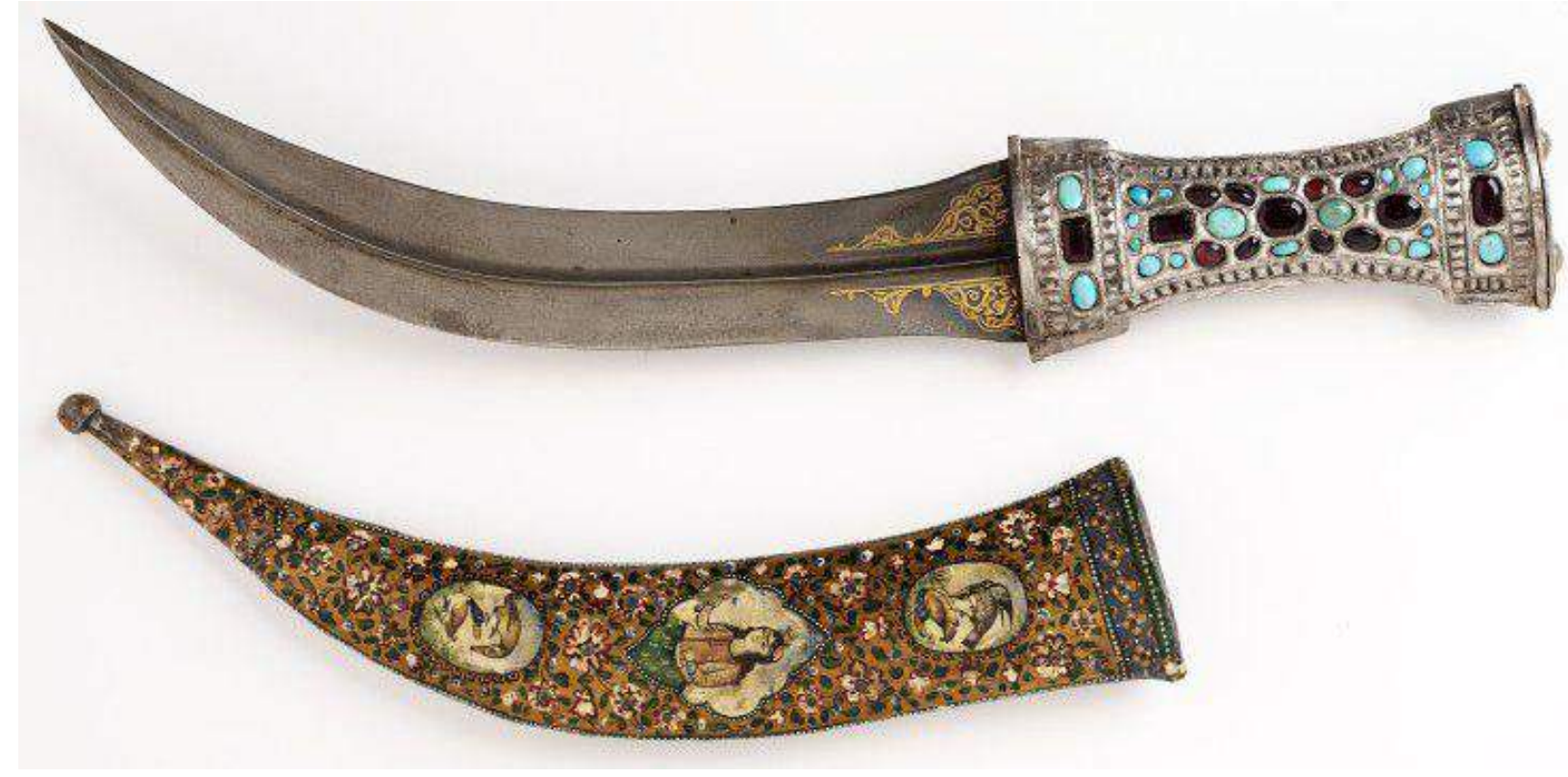

manche en argent, le fourreau en bois laqué (début du XIX ${ }^{\text {ème }}$ siècle) Pl. 4- Poignard en acier et Musée Victoria \& Albert $\mathrm{N}^{\circ}{ }_{582 \mathrm{~A}-1876}$ 


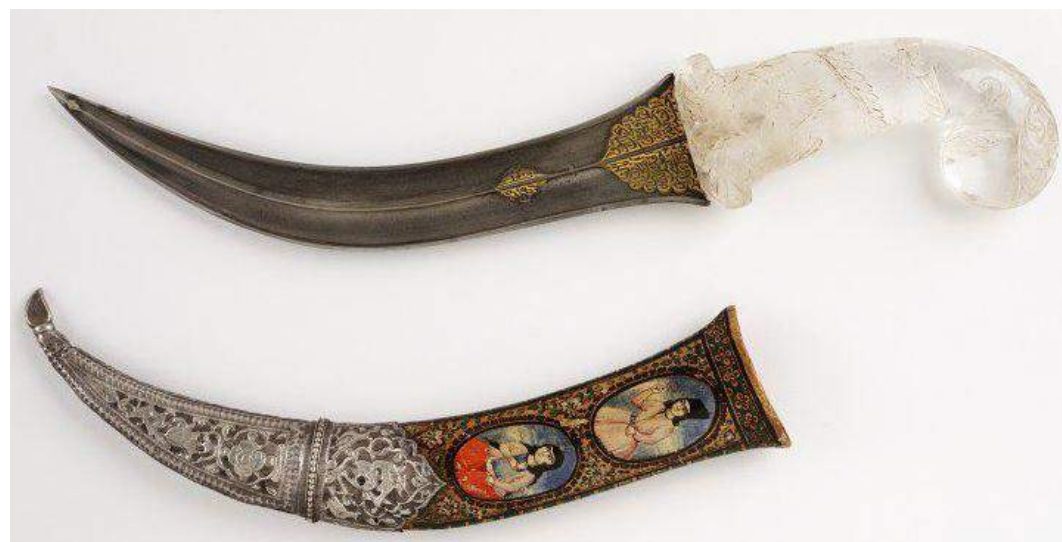

Pl. 5- Poignard en acier et manche en cristal de roche, le fourreau en bois laqué avec une chape en argent ciselé

Musée Victoria \& Albert $\mathrm{N}^{\circ}$ 720A- 1889.

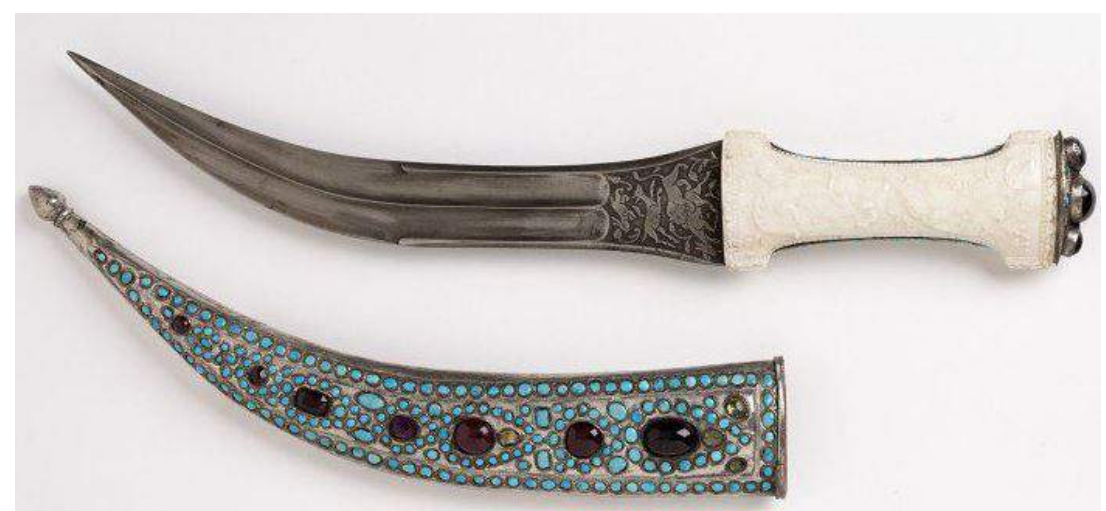

Pl. 6- Poignard en acier et manche en ivoire, le fourreau en argent incrusté de pierres précieuses. Musée Victoria \& Albert $N^{\circ}$ 573A-1876.

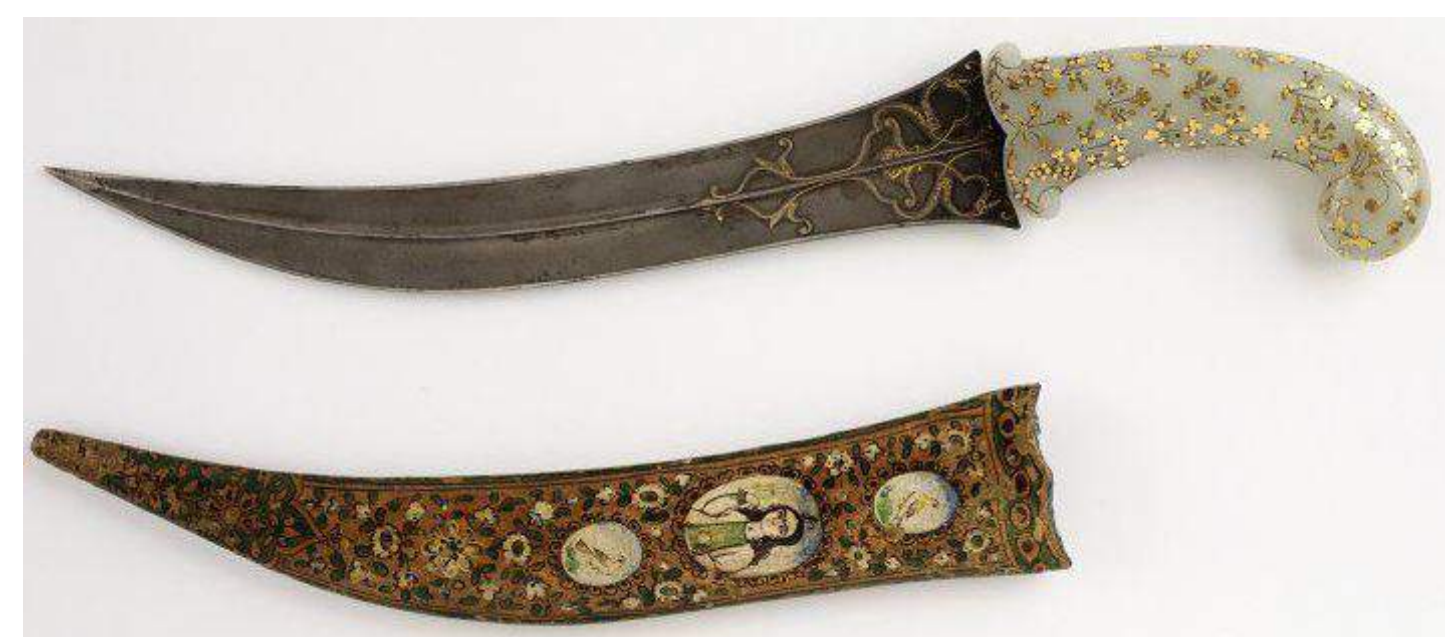

Pl. 7- poignard courbé à double tranchant, manche en jade vert et fourreau en bois laqué polychrome

Musée Victoria \& Albert $N^{\circ} 712 \& A-1889$ 

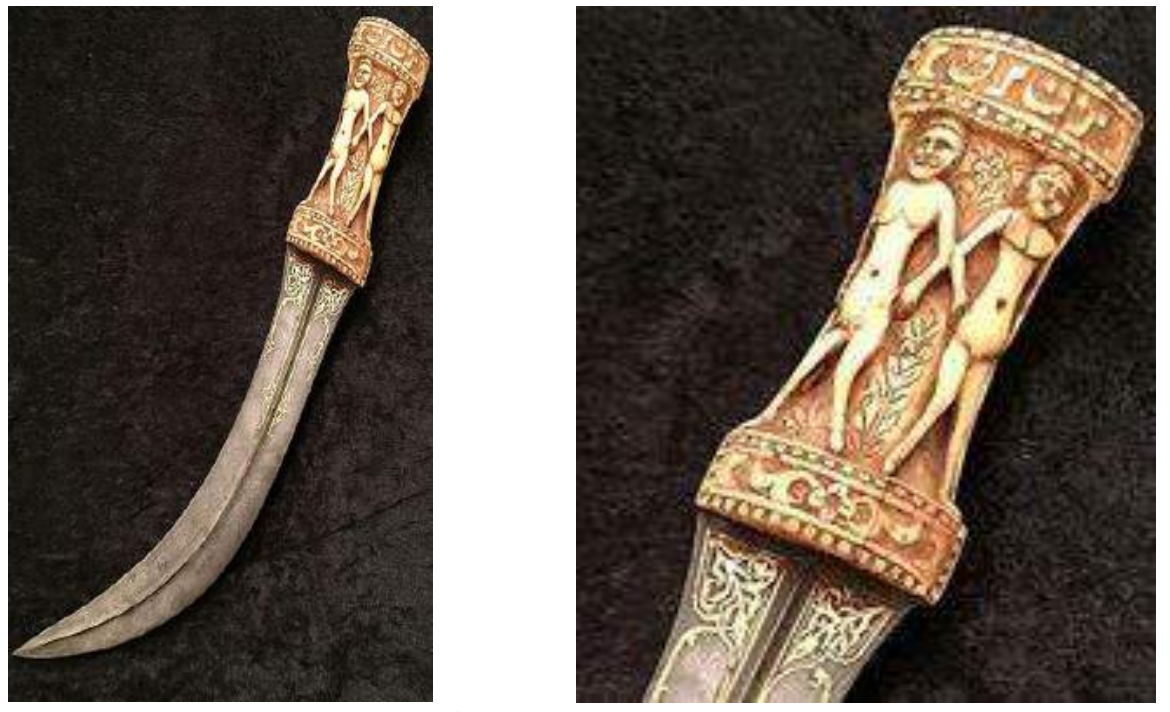

Pl. 8.B

Pl. 8.A

Poignard en acier damasquiné, manche en ivoire avec représentation figurative en relief Musée National d'Art d'Azerbaïdjan

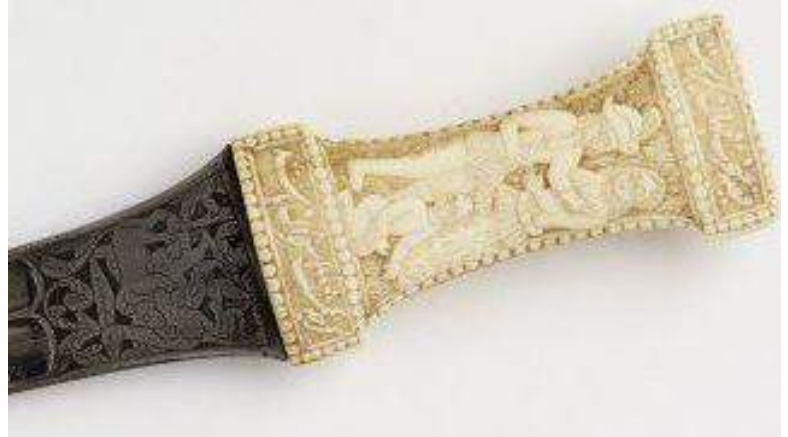

Pl. 9.A- Détails du manche en ivoire

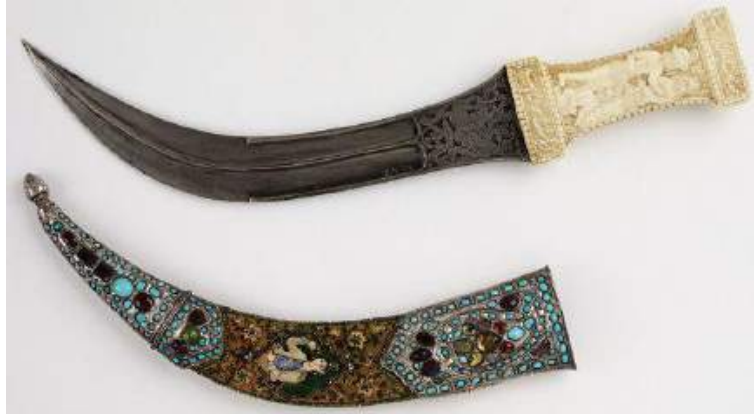

Pl. 9.B- poignard et fourreau

Poignard en acier damasquiné, manche en ivoire avec représentation figurative en relief Musée Victoria \& Albert $\mathrm{N}^{\circ} 574 \mathrm{~A}-1876$. 


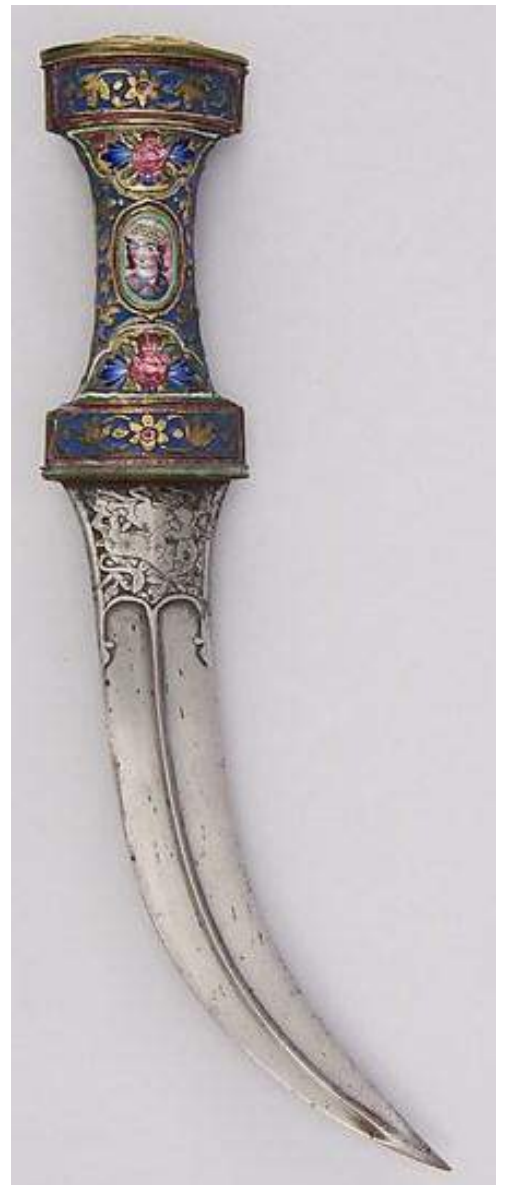

Pl.1o.A - Représentation figurative Poignard en acier, et manche en cuivre émaillé

Metropolitan Museum of Art $\mathrm{N}^{\circ}$ 36.25.683

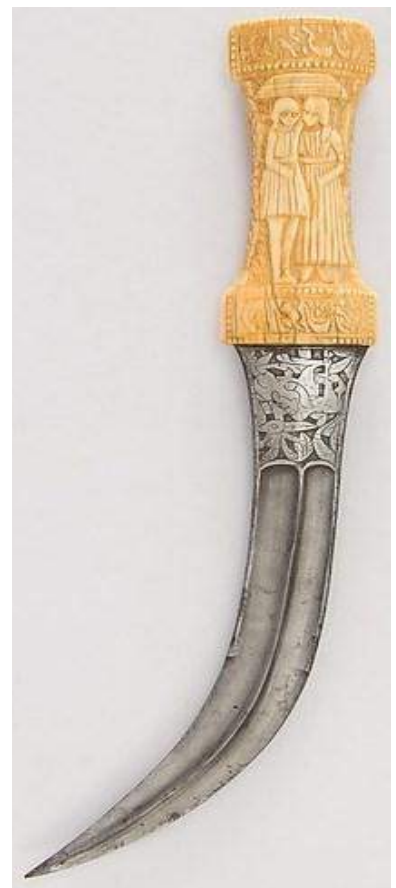

Pl.11.A- Un couple d'amants

Poignard en acier, manche en ivoire

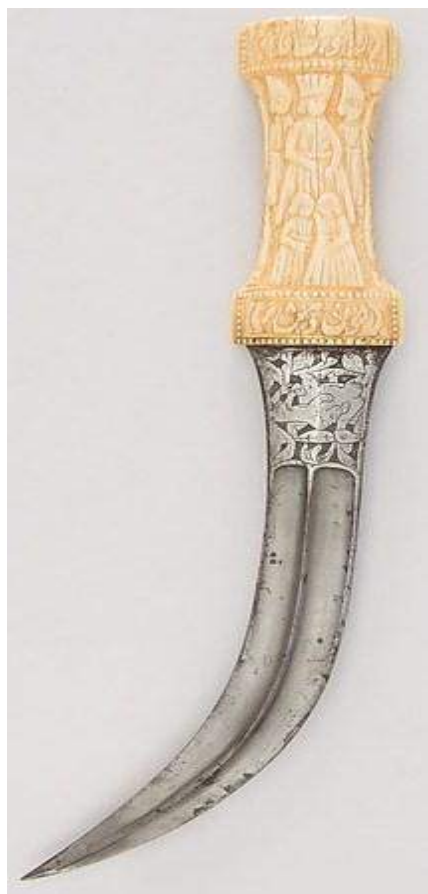

Métropolitain Museum of Art $\mathrm{N}^{\circ}$ 36.25.1058 


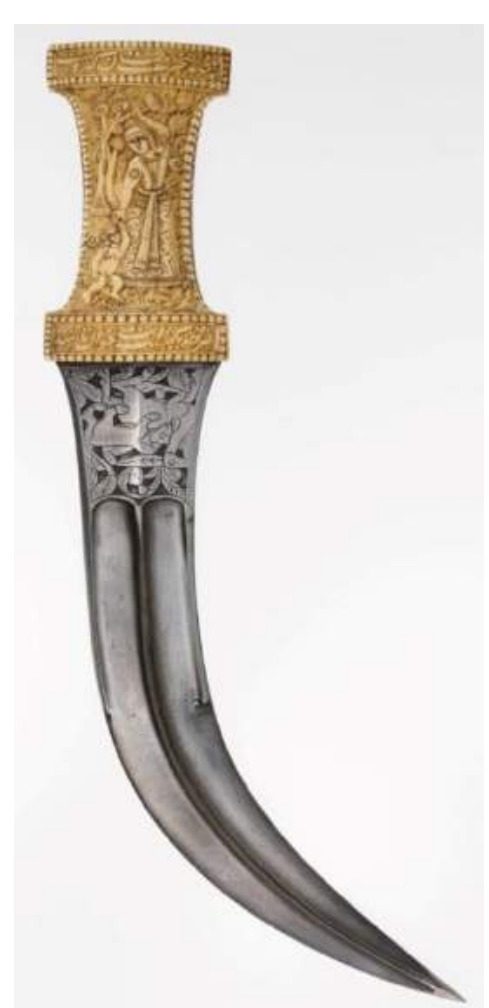

Pl. 12-A Lame en acier, poignée en ivoire

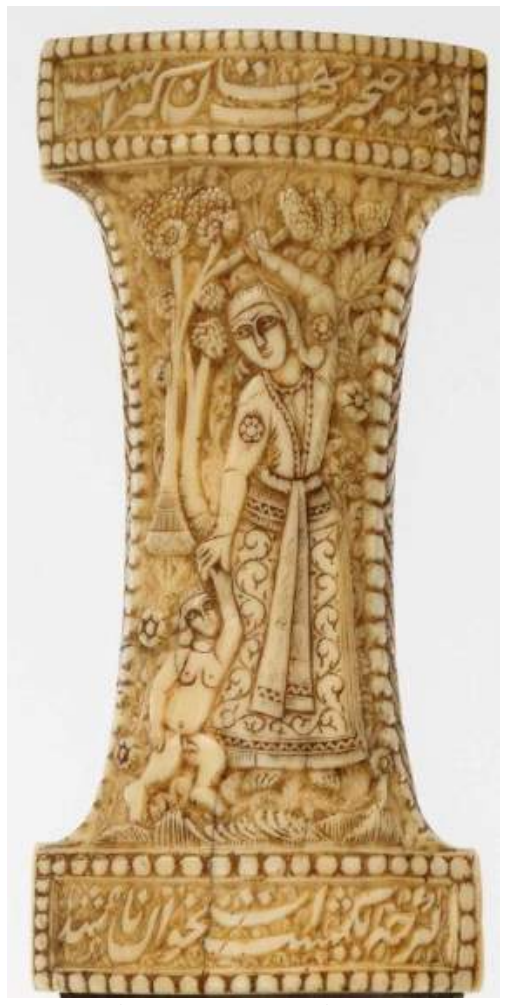

Pl. 12.B- Une dame tenant un enfant

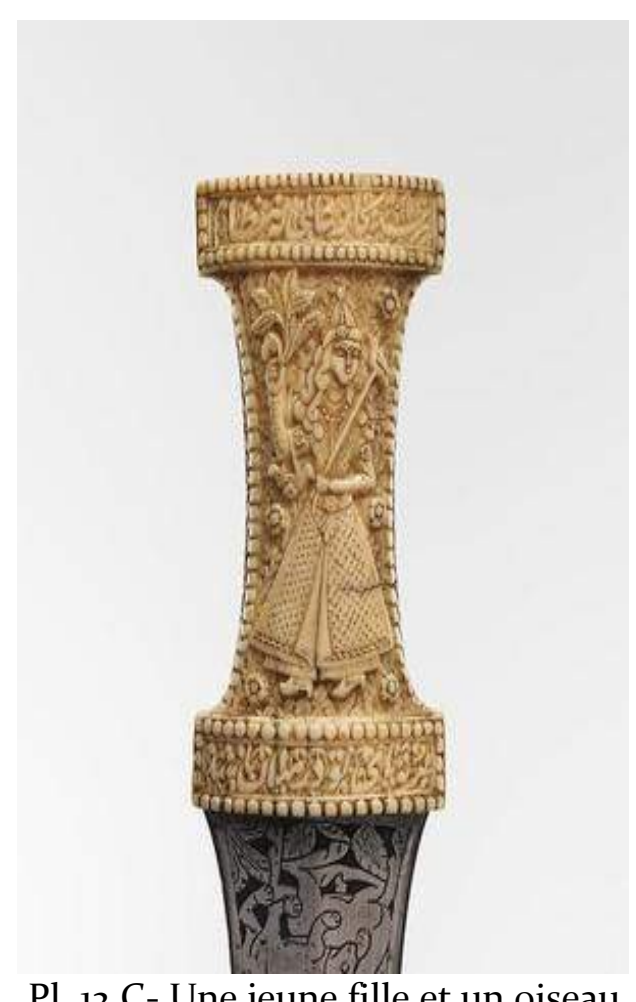

Pl. 12.C- Une jeune fille et un oiseau

1. Les Qājārs - nom voulant dire en turc «qui marche rapidement»-sont une tribu d'éleveurs nomades turcophones anciennement installés au nord de la Perse, dans la région d'Astarābād. Ils jouissaient, au service des Safavides (1501-1722), d'une importance militaire notable. Après la chute de cette dynastie, lors des guerres intérieures qui ont déchiré la Perse au XVIIIe siècle, les Qâjârs étaient des alliés importants pour les 
princes qui voulaient dominer sur le nord du pays. «Ağā Muhammad Khān», un prince qui est a pu devenir maître de tout le nord de la Perse jusqu'à Ispahan; a fait de Téhéran, petite bourgade au pied de la montagne, sa capitale en 1786. C'est là qu'il se fait couronner dix ans plus tard, après avoir conquis la Géorgie. Lorsqu'il a été assassiné en 1797, le pouvoir a été transféré à son neveu Fatḥ-'Alī Šāh, et l'Iran, dès 1778, était redevenu une entité politique sur laquelle régnait une puissante dynastie.

- Sykes, P., A History of Persia, London, 1921, p. 293-295.

- Encyclopedia of Islam, Vol. II, London, 1960, p. 838.

- Brockelmann, C.; History of Islamic People, Routledge \& Kegan Paul, London \& Henley, 1982, p 416.

2. Hassan, S., Funūn al- Tașwīr al- İrānī, Université de Helwan, le Caire, 2016, p. 13.

3. Ibid, p. 10.

${ }^{4}$. Nāṣir al- Dīn Šāh, qui a voulu être très attaché aux européens, n'a pas hésité à vendre des pans entiers des richesses nationales à des sociétés étrangères; en accordant en 1872 au baron de Reuter, le monopole des chemins de fer, des mines, de l'irrigation, de la banque, et divers projets agricoles et industriels, de même, en 1890, il vend à Talbot le monopole du commerce et de la manufacture des tabacs.

Le clergé chiite a fortement appuyé sur le refus populaire de cette nouvelle ingérence européenne pour obliger le Šāh à reculer en rachetant le monopole.

- Richard, Y., L'Iran sous les Qâjar (1779-1925), p. 20.

- Hillenbrand, R., Persian Painting from the Mongols to the Qajar, I. B. Tauris, 2001, p. 85.

${ }^{5}$. Zadeh M. M; Le rôle des artistes - peintres dans le développement de la peinture qâdjâr, dans La revue de Tehran, $\mathrm{N}^{\circ} 23$, octobre 2007, p. 30.

6. Yassīn, I., Al- Ta'tîrāt al- Urubiyya 'ala al- Funūn al- Islāmiyya al- Irāniyya khilāl al- 'Aṣr al- Qājārī, Thèse de Majistère, Université du Caire, 2008, p. 19-24.

7. 'Afîfî, A., Mawsou'at 1000 madīna islāmiya, al- Dār al- 'Arbiyya l'il Kitāb, 2000, p. 103.

- Yassīn, I., Al- Ta'tīīāt al- Urūbiyya, p. 12-15.

${ }^{8}$. L'irruption de la culture, des goûts, et de la peinture européenne, dans la société qājāar, a incité le peintre à redéfinir ses repères identitaires, c'est ainsi qu'un certain nombre de peintres se sont dégagés de l'exclusivité de la cour, ont sorti de la domination conceptuelle des livres de littérature et se sont posés comme indépendants du style aristocrate qui marque l'art de la cour.

- Zadeh M., M; Le rôle des artistes - peintres, p. 32.

9. Sardar, M., The Arts of Iran, 1600-1800, In Heilbrunn Timeline of Art History, New York, The Metropolitan Museum of Art, 2000.

${ }^{10}$. Ibn Abī Shība, Muṣannaf, Kitāb al- Gihād, hadīith No. 18764.

${ }^{11}$. Elgood, R., Arms and Armour of Arabia in the 18th-19th and 20th Centuries, London, 1994, p. 59.

12. Les entrepôts du calife Abbasside «Hārūn al- Rashīd» était énuméré à sa mort en 193/809 sur les ordres de son fils, un processus qui a pris quatre mois, et parmi beaucoup d'articles ont contenu 10000 épées décorées, 50000 épées pour ghulāms), 150000 lances, 100000 arcs, 1000 armures spéciales, 50000 armures ordinaires, 10000 casques, 20000 plaques de poitrine, 150000 boucliers.

- Ibn al- Zubayr, Kitāb al- Dhakhā'ir wa'l- Tuhaf, p. 214-218.

13. Abdallah, S., Al- Tuhaf al- Ma daniyya al- Șafawiyya fĩ Du' al- Tuhaf al- Ṭaṭīqiyya wa Șuwar alMakhțūtật, Thèse de Magistère, Faculté d'Archéologie, Université du Caire, 2004, p. 57.

${ }^{14}$. Elgood, R., Arms and Armour, p. 60-62.

${ }^{15}$. Hassan, Z., Al- Funūn al- Irāniyya fĩ al- 'Așr al- Islāmī, Dār al- Rā' id al- 'Arabī, Beirut, 1981, p. 284.

16. Farghalī, A., Al- Funūn al- Zuhrufiyya al- Islamiyya fì 'Așr al- Șafawiyyīn bi Irān, maktabat Madbūlī, 1989, p. 196.

17. "Kārd" est un terme persan, dérivé du verbe "kareta" qui veut dire (couper), c'est une arme sous la forme d'un couteau, court, à un seul tranchant, et sa lame pouvait être toute droite ou courbée.

- Khorasani, M. M., Edged Weapons: The Persian Kārd, In Classic Arms and Militaria, Vol. XV, Issue 2, 2008 , p. 25.

${ }^{18}$. Khorasani, M.M., The Khanjar, Dagger of the Ayyārān, in Classic Arms and Militaria, Vol. XIV, Issue 6, p. 25 .

${ }^{19}$. Hassan, S., Funūn al- Tașwīr al- İrānī, p. 273.

${ }^{20}$. Hassan, Z., Al- Funūn al- Irāniyya, p. 258.

${ }^{21}$. Abdallah, S., Al- Tuhaf al- Ma daniyya, p. 55-56. 
${ }^{22}$. Les poignards courbés ont suivi la même évolution des épées, signifiant qu'ils étaient initialement à double couture et droit, mais a gagné plus tard une légère courbure.

- Khorasani, M. M., The Khanjar, p. 26.

${ }^{23}$. Le terme «acier damassé» ou «acier de Damas» est appliqué sur des épées, des poignards, constitués de plusieurs nuances d'acier soudés et forgés; obtenu à partir d'un procédé originaire fondé sur la fusion prolongée de fragments de fer avec du charbon, puis le trempage et forgeage de l'amalgame créé, les moirures obtenues par la frappe de cet acier lui ont donné le nom d'acier «damassé».

- Zaki, A. R., Introduction to the Study of Islamic Arms and Armour, In Gladius, I, 1961, p. 23.

- Durand-Charre, M., Les aciers damassés: Du fer primitif aux aciers modernes, Presses des Mines, Paris, 2007, p. 18.

${ }^{24}$. Khorasani, M. M., Curved double- edged Persian Dagger, In Echo of Islam, № 218, June- July 2009, p. 19.

25. L'Iran jouissait à cette époque d'un environnement artistique et organisationnel restrictif, qui explique aussi pourquoi l'art de peindre, ou pour n'importe quel métier, a été dominé par un petit nombre de familles. À Kashan, la famille «Ghaffari» était le premier producteur de peintres de haut niveau. Apparemment, ces familles d'artisans se sont mutuellement entretenus et ont eu d'autres contacts sociaux étroits, comme le mariage, et il est clair que ces familles «artistiques» avaient été engagées dans leur métier pendant de nombreuses générations.

- Floor, W., Art (Naqqashi) and artists (Naqqashan) in Qajar Persia, in Muqarnas, vol. 16, 1999, p. 126.

${ }^{26}$. Durand-Charre, M., Les aciers damassés, p. 39.

${ }^{27}$. Lévesque, R., «Marqueterie», Encyclopædia Universalis [en ligne], URL:

http://www.universalis.fr/encyclopedie/marqueterie/

${ }^{28}$. Georges, C., L'ncrustation sur métal et l'orfèvrerie cloisonnée en Mésopotamie, In: Syria, T. 33, 1956, p. 58.

${ }^{29}$. Hassan, S., Funūn al- Tașwīr al- Īrānī, p. 207- 210.

${ }^{30}$. Maher, S., Al- Funūn al- Islāmiyya, Maktabat al- Usra, Le Caire, 2005, p. 238.

${ }^{31}$. Robinson, B. W., Qajar Painted Enamels, In Paintings from Islamic Lands, ed. R. Pinder-Wilson, Oxford, 1969, p. 187-204.

32. Al- Bukhārī, Gawāhir al- Bukhārī, Ḥadīth Nº 3226.

33. Yassīn, I., Al- Ta'tīinăt al- Urubiyya, p. 230.

${ }^{34}$. Roux, J. P., Le Combat d'Animaux dans 1'Art et la Mythologie Irano- Turcs, In: Arts asiatiques, T. 36, 1981, p. 8.

35. La chaîne de propriété de l'épée à partir de ce moment cesse et l'épée a disparu même si divers groupes revendiquent la possession et l'autorité que cela leur a donné. Puis, l'épée est passé, par héritage, à la dynastie Abbasside pendant longtemps. Deux chiites affirment que l'épée est restée dans la famille Alid jusqu'à 873 J.C. quand le douzième Imam a disparu.

- Elgood, R., Arms and Armour, p. 15.

36. Khorasani, M. M., The Lion, the Bull and the Sun: Emblems of Power, In Classic Arms and Militaria, Vol. XIX, Issue 2, April/May 2012, p. 16-17.

37. Yassīn, I., Al- Ta'tīrāt al- Urubiyya, p. 235.

${ }^{38}$. Hassan, S., Funūn al- Tașwīr al- İrānī, p. 55.

39. Durant l'évolution de la représentation de la femme sur les œuvres artistiques, l'artiste avait tendance à diminuer le nombre d'hommes dans le cadre en faveur du nombre de femmes, de surcroît, il avait l'audace de la représenter portant des tenues révélatrices, un de ces plus célèbre artiste était «Réda 'Abbas».

- Ibrahim, H., Tașāwīr al- Mara fĩ Irān fī al - 'Așrayn al- Taymūrī w’al Șafawī min hilāl al- Maḥțutūāt w’al funūn al- tațbīqiyya, Thèse de Magistère, Faculté d'Archéologie, Université du Caire, 2006, p. 276-277.

40. «Fath 'Alī Šāh» était connue par son amour pour les femmes, on disait qu'il avait environ sept cents épouses et concubines et qu'il a eu soixante- quatre fils et cent vingt-cinq filles.

- Hassan, Z., Al- Funūn al- Irāniyya, le Caire, 1940, p. 51.

${ }^{41}$. Hassan, S., Funūn al- Tașwīr al- İrānī, p. 11.

- Falk, S. J., Qajar Paintings, A Catalogue of Qajar Paintings of the $18^{\text {th }} \& 19^{\text {th }}$ Centuries Paintings, London, 1972, p. 34.

42.'Atțallah, N., Al- Tuhaf al- Ma'daniyya al- İrāniyya fil 'Aṣ̂r al- Qājārī, Thèse de Mahistère, Faculté d'Archéologie, Université du Caire, 2013, p. 283. 
${ }^{43}$. Hassan, S., Funūn al- Tașwīr al- İrānī, p. 63.

${ }^{44}$. Meen, V. B.; Tushingham, A. D., Crown Jewels of Iran, Toronto, 1968, p. 90.

${ }^{45}$. Singh, A.; Khorasani, M. M., La signification des motifs à fleurs sur les armes et armures iraniennes, Dans La revue de Teheran, $\mathrm{N}^{\circ} 75$, février 2012, p. 6.

46. Alexander, D. G., Islamic Arms and Armor in The Metropolitan Museum of Art, Met Publications, 2015, p. 83.

47. «Beglarbegī» est le nom du grand-père maternel de Muḥammad Šāh.

${ }^{48}$. Hassan Khān a été nommé Ağā Khān, chef de la secte Nizārī Ismā ̂̀ì de l'islam chiite, par le prédécesseur et grand-père de Muhammad Šāh, «Fatḥ 'Alī Šāh», en 1838, il a mené une révolte contre Muhammad Šāh à Kirman, et a finalement été battu et exilé en Inde. Ainsi, la poignée de ce poignard, que l'Ağā Khān avait commandé spécifiquement pour montrer sa relation étroite avec le Šāh, doit avoir été faite avant la révolte de 1838 .

- Mortimer, K. A., Harvard University Art Museums: A Guide to the Collections, Harvard University Art Museums, Abbeville Press, Cambridge, New York, 1985, p.84, fig.89.

${ }^{49}$. Mayer, L. A., Islamic Armourers and Their Works, Geneva, Albert Kundig, 1962, p.57.

${ }^{50}$. Alexander, D. G., Islamic Arms and Armor in the Metropolitan Museum, p. 79. 